\title{
A classe média vai para a escola pública
}

AdALBERTO WodiAnER MARCONDES*

Uma das decisões mais dificeis para as famílias de classe média, nos últimos anos, tem sido matricular os filhos em uma escola pública, principalmente para aquelas que acreditam na necessidade de oferecer ensino de qualidade para que os filhos "tenham chance" de entrar qualificados no mercado e construir vidas melhores. No entanto, apesar de difícil, essa é uma decisão que está sendo tomada por um número cada vez maior de pais que, por um motivo ou outro, não conseguem mais bancar os custos do ensino privado e batem às portas da escola pública, com dor no coração e entregando o futuro de seus filhos ao Estado. Esse foi o caminho que me levou até a porta da Escola Estadual Prof. Antônio Alves Cruz para matricular minha filha mais nova, no terceiro ano do ensino médio, em 2004.

O Alves Cruz é uma escola com história. Tem entre seus ex-alunos alguns bem-sucedidos empresários, médicos e executivos, que hoje atuam em uma ONG chamada Projeto Fênix, que auxilia em programas na escola. Mas isso eu só vim a saber algum tempo depois de fazer a matrícula. 0 que me levou a escolher o Alves Cruz não foi apenas a sua proximidade com a minha casa, como também a sua localização em uma belíssima praça, ao lado da avenida Heitor Penteado, no Jardim das Bandeiras, um dos bairros mais nobres de São Paulo. Até ali, eu ainda esperava que a escola, por osmose, pudesse absorver alguma coisa da classe média que a rodeia.

Os protestos da minha filha ecoaram em minha cabeça e, de alguma maneira, era preciso encontrar meios para aplacar a culpa que se espalhava dentro de mim. A senha foi um bilhete da escola convocando os pais para uma reunião na qual seria eleita a nova diretoria da As-

\footnotetext{
* Adalberto Wodianer Marcondes é jornalista, diretor e editor da agência de notícias ENVOLVERDE e foi presidente da Associação de Pais e Mestres da Escola Estadual Profo Antonio Alves Cruz durante dois anos. Coordena o Núcleo de Comunicação do CENPEC.
}

sociação de Pais e Mestres. No dia, com o melhor espírito de cidadania em punho, rumei para a escola, acompanhado de minha esposa, psicopedagoga. Afinal, pensava eu, sou fruto da escola pública. Primário, ginásio, colégio e universidade à custa do contribuinte. Ora, era hora de devolver um pouco do que recebera, naquela época, com boa qualidade.

Este foi o início de uma experiência de quase dois anos como diretor executivo - equivalente a presidente - da Associação de Pais e Mestres da Escola Estadual Professor Antônio Alves Cruz. E, também, o despertar do interesse sobre a atuação dos pais na escola publica, como ela acontece e, principalmente, por que não acontece.

0 debate sobre educação integral deve, também, ser enriquecido com o caráter e a qualidade da participação dos pais de alunos, dos professores, de organizações da sociedade civil e dos próprios alunos na gestão das escolas públicas. A lei já determina algumas instâncias de participação institucional: a APM, o Grêmio Estudantil e o Conselho de Escola. Essas instâncias decisórias e deliberativas devem existir em todas as escolas públicas do Brasil. Entretanto, não basta a lei.

\section{Boicote institucional}

\section{Um dos obstáculos à participação da comunidade na} escola é o despreparo da estrutura do Estado, incluído diretores e professores, em acolher e aceitar essa participação. É vista mais como ingerência do que como contribuição. E os conflitos são permanentes: com o diretor, por conta das prioridades de gestão; com os professores, por conta de o Conselho da Escola ter a prerrogativa de discutir e votar o projeto pedagógico.

Portanto, o boicote vem institucionalmente. Em maior ou menor grau, os diretores não demonstram boa vontade em relação a uma APM ativa. No caso do Alves Cruz, a primeira impressão foi horrível. No dia da eleição, convo- 
cada com atraso de quase um ano, poucos pais se dignaram ou puderam sair de suas rotinas para ir eleger uma APM. Afinal, para que serve uma APM? Pouco mais de meia dúzia de pessoas esperou por mais de uma hora que o diretor aparecesse para fazer as honras da casa e explicar o que, afinal, estávamos fazendo lá. Depois de 15 minutos, nós já sabíamos que a APM era um estorvo para a gestão da escola, na opinião daquele diretor (e, descobri depois, de muitos outros).

"Vamos apenas fazer a ata, dizendo que a eleição aconteceu, e depois eu arranjo os nomes para compor a diretoria da APM", propôs o diretor para aquela meia dúzia de pais que esperavam estar ali cumprindo algum viés de cidadania. Foi a indignidade da proposta que se encarregou de mobilizar os pais para tentar realizar uma eleição representativa e democrática. Conseguimos reunir cerca de 50 pais, uma semana depois, em uma escola com 700 alunos. De qualquer forma, foi muito mais representativo do que a meia dúzia de uma semana antes.
Desses dois anos de experiências boas com os alunos e muito frustrantes com a gestão do ensino público, veio-me a constatação de que não existem saídas para a educação sem o acolhimento real da família e da comunidade na escola. Essa participação não pode ser concebida apenas como "mão-de-obra barata" para mutirões de limpeza, de pintura, de jardinagem e outros. Deve-se promover o "empoderamento" para a gestão efetiva das unidades escolares, com a construção democrática das instâncias deliberativas e gestoras e, principalmente, o preparo dos delegados de ensino, diretores e professores para que não se sintam violentados em seus direitos e atividades.

0 antagonismo que se forma quando existe a participação da comunidade é fruto, principalmente, de desinformação de lado a lado e da incapacidade de se fazer o gerenciamento dos conflitos, principalmente de interesses. 0 diretor deve dividir as decisões de gestão, os professores precisam seguir um projeto pedagógico de-

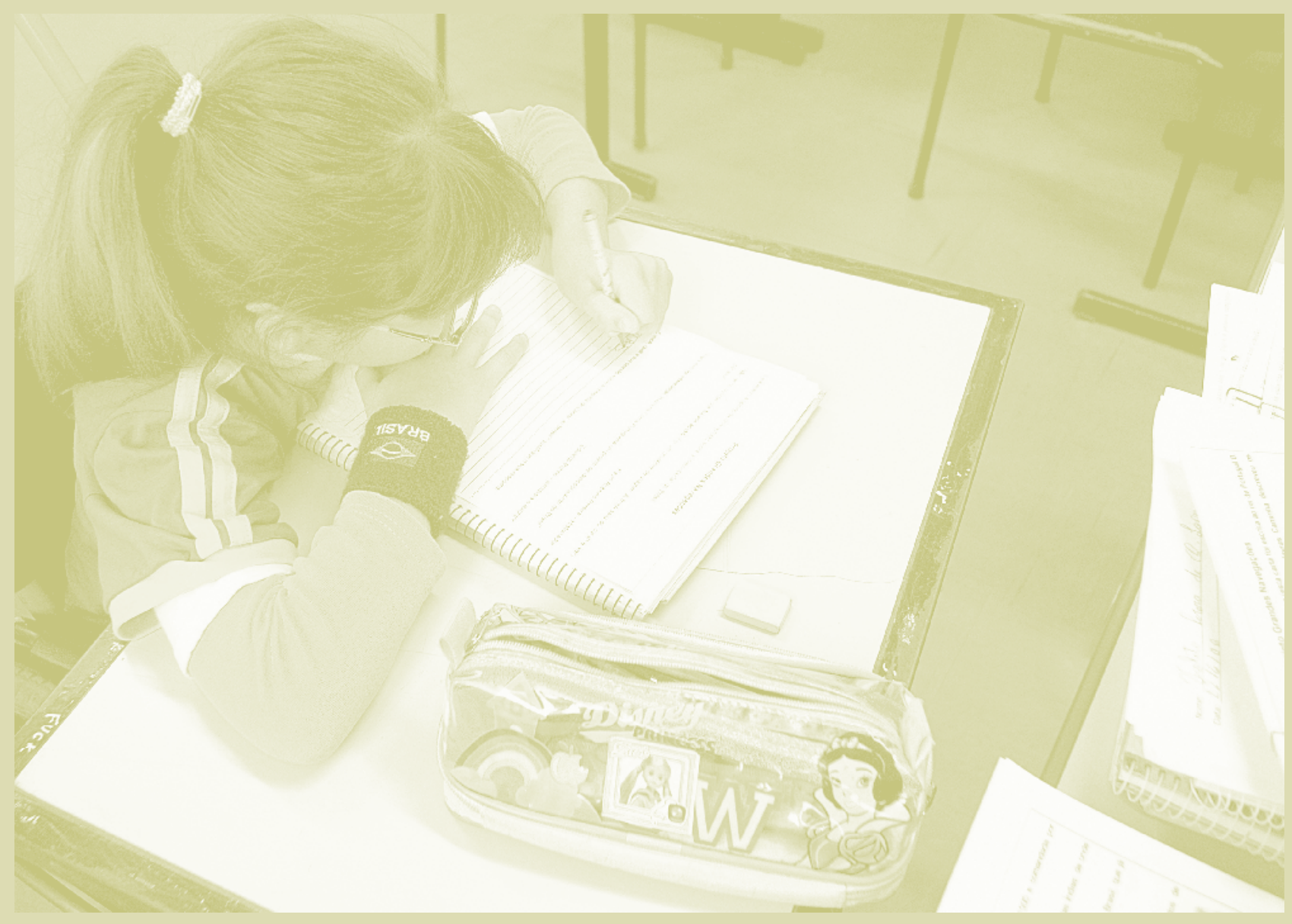




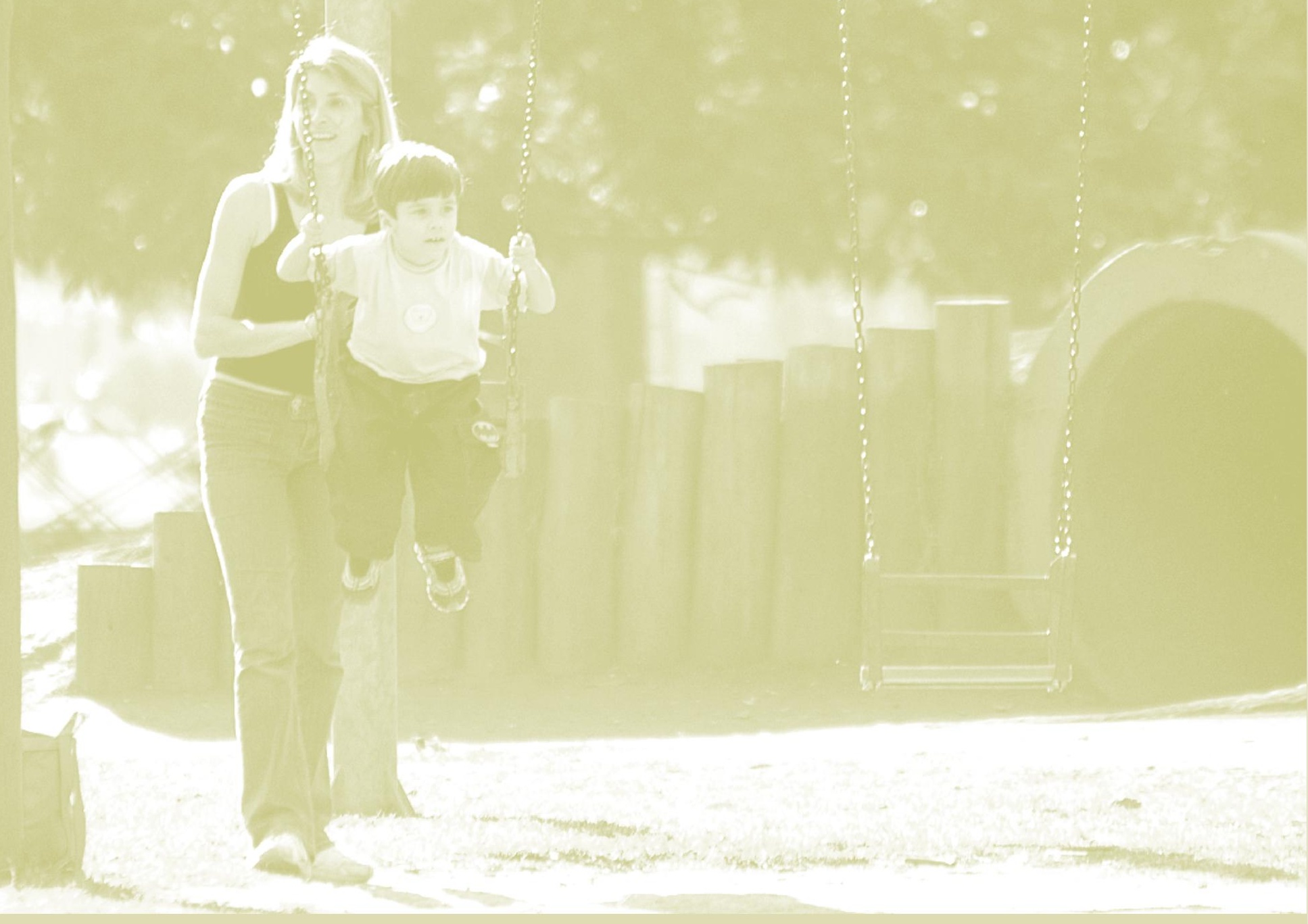

cidido democraticamente e os pais têm de se responsabilizar pela qualidade da escola e do ensino oferecido a seus filhos.

É muito fácil falar em democracia quando o único gesto necessário é usar o Título de Eleitor a cada quatro anos para eleger representantes e, depois, sentar-se sobre a opinião de que as coisas públicas são ineficientes por definição. A educação, por meio da escola pública, é talvez a mais importante presença do Estado na sociedade, certamente, mais do que a polícia e o exército. Está em todas as comunidades e precisa delas para cumprir seu papel de construção do futuro e da cidadania de milhões de jovens. Delegamos não ao Estado, e sim a uma burocracia despreparada e descomprometida, a gestão da construção de um futuro alternativo, quando a lei oferece os caminhos para que a sociedade assuma suas responsabilidades na gestão cotidiana do ensino público e utilize adequadas ferramentas para que a boa qualidade seja um fato, e não apenas um desejo, na escola pública.

Mas a estruturação dessa participação, que permitirá a construção da integralidade no ensino, tem de ser inclusiva e estar em consonância com o querer de cada uma das múltiplas partes envolvidas. Esse querer existe no discurso oficial, na letra da lei, na vontade de algumas comunidades e pode ser um grande aliado dos gestores e professores. A pressão à qual estão expostos esses profissionais em um duro cotidiano de problemas e riscos pode ser minimizada com a inclusão da família e da comunidade na busca de soluções.

O olhar da família sobre a escola pública é, em grande parte, de desesperança. A construção das pontes necessárias para que as APMs e os Conselhos de Escola consigam assumir as responsabilidades para as quais foram idealizados é um trabalho árduo e não terá sucesso rápido, nem em todas as comunidades ao mesmo tempo. Mas os espíritos precisam se desarmar. Nem a educação é somente uma obrigação do Estado, nem a família é simplesmente mão-de-obra barata para mutirões.

As estruturas concebidas pelo Estado para a participação da comunidade na escola são esquizofrênicas. Por um lado, impedem a escola de funcionar sem qualquer presença comunitária, porque algumas verbas somente podem ser utilizadas pela APM. De outro lado, não oferecem apoio institucional para o fortalecimento da participação da comunidade nas APM. 


\section{O que é uma APM?}

APM - Associação de Pais e Mestres, e similares - pessoa jurídica de direito privado, é um órgão de representação dos pais e profissionais do estabelecimento, não tendo caráter político partidário, religioso, racial e nem fins lucrativos.

\section{Quais são seus objetivos?}

Integrar a comunidade no contexto escolar, promovendo encontros de pais para refletirem sobre a política educacional vigente, visando sempre a realidade dessa mesma comunidade.

Representar os reais interesses da comunidade e dos pais de alunos junto à Direção do estabelecimento de ensino, contribuindo com sugestões para adoção de medidas que se julgarem necessárias, respeitando as decisões tomadas pelo Conselho Escolar.

Colaborar para o sucesso de ações previstas no Projeto Pedagógico do estabelecimento de ensino, voltadas para a assistência ao educando, ao aprimoramento do ensino e para a integração família - escola - comunidade.

Discutir, colaborar e decidir sobre as ações para a assistência ao educando, o aprimoramento do ensino e para a integração família - escola - comunidade.

Promover o entrosamento entre os pais, alunos, professores e membros da comunidade, através de atividades socioeducativas, culturais e desportivas, de comum acordo com a Direção do estabelecimento de ensino e aprovação do Conselho Escolar.

Contribuir para a melhoria e conservação do aparelhamento do estabelecimento escolar, sempre dentro de critérios de prioridade, sendo as condições dos educandos fator de máxima prioridade.

Promover palestras, conferências e círculos de estudos, envolvendo pais e professores, a partir de necessidades apontadas por esses segmentos.

\section{A realidade das escolas}

\section{Esse texto, distribuído pela Secretaria de Educação do}

Estado do Paraná, mostra de uma forma empírica e ideal o que seria uma Associação de Pais e Mestres. Muitas vezes, talvez na maioria, a realidade é que a APM é um instrumento manipulado pela direção da escola para atender a seus objetivos próprios. É desestimulada a realizar qualquer atividade dentro da escola para que sua gestão se desgaste $e$ termine no abandono da maioria dos mandatos de APM.

$O$ cotidiano das relações entre pais, diretores e professores é muito conflituoso e quem perde são os alunos. Esse conflito existe principalmente porque as interfaces são de cobrança de parte a parte. Pais acusam professores de faltar muito, diretores acusam pais de omissão e ingerência, a assim vai a cascata que deságua em alunos indisciplinados e desinteressados.

Quando a comunidade se mobiliza e aceita assumir responsabilidades em relação à escola descobre que o Estado não está preparado para acolher essa participação. Não existem instrumentos de apoio à atuação da família e da comunidade na escola. Não há a quem recorrer para a construção dessa participação; as delegacias de ensino não são capazes de absorver as demandas da sociedade engajada e as secretarias de educação apenas informam a letra da lei. Facilitaria muito o trabalho de todos - pais, diretores, professores e alunos - se existisse alguma instância de apoio às APMs, aos Conselhos de Escola e aos Grêmios Estudantis.

O Estado, como gestor e financiador da Educação, tem a capacidade de oferecer o suporte necessário, com a formação e capacitação para todas as partes envolvidas nessa gestão integral da escola pública. Não basta a lei, é preciso garantir a transferência e o intercâmbio de experiências e conhecimento, para que as boas práticas possam ganhar amplitude e eco.

A integralidade do processo educativo precisa que todos os envolvidos busquem a integração de propósitos e a negociação de seus conflitos. Enxergar a escola como um campo neutro, onde apenas os grandes ideais da educação devem florescer, é ingenuidade. A escola é mais um dos lugares onde os conflitos da sociedade de manifestam, onde o corporativismo dos professores se choca com as cobranças de pais e alunos, onde os conflitos da família são jogados nas costas do Estado e onde a sociedade, por mais difícil que seja compreender, deve depositar suas esperanças de futuro. 
